American Journal of Applied Sciences 6 (6): 1122-1125, 2009

ISSN 1546-9239

(C) 2009 Science Publications

\title{
The Effects of Excess Oxygen to Mixture on the Gasses Emissions of a Gasoline Engine
}

\author{
Waleed Momani \\ Department of Mechanical Engineering, Faculty of Engineering Technology, \\ Al Balqa Applied University, Amman, Jordan
}

\begin{abstract}
Problem statement: The effects of excess feeding oxygen to the fuel-air mixture on the exhausts gasses emissions concentrations are investigated here. It is known that spark-ignition and diesel engines are considered as major sources of urban air pollution; such pollutants are $\mathrm{CO}_{2}, \mathrm{CO}, \mathrm{HC}$. Hence, many techniques have been used to decrease such emissions such as: Catalytic converters, oxidizers, traps and Diesel Particulate Filters (DPF), but these techniques have some disadvantages represented by: Forming back pressure which affects the engine performance, plugging and high costs. Approach: In present study the effects of feeding more oxygen to the combustion mixture is studied experimentally. Results: It was found from tests applying on an engine that excess oxygen has positive results in decreasing concentration of both $\mathrm{CO}$ and $\mathrm{HC}$ 's. Conclusion/Recommendations: $\mathrm{CO}_{2}$ concentration at oxygen injection test is greater than that at without oxygen injection at the two cases: With load and without load tests and at nearly all engine speeds. CO concentration at oxygen injection test is much less than that at without oxygen injection at the two cases: With load and without load tests and at nearly all engine speeds. HC concentration at oxygen injection test is less than that at without oxygen injection at the two cases: With load and without load tests and at nearly all engine speeds. It also recommended using more amount of oxygen in the future to find the optimal value of oxygen can be fed and if anther fuel additives can be used.
\end{abstract}

Key words: Fuel-air mixture, exhaust emissions, excess oxygen feeding

\section{INTRODUCTION}

If you look for minutes and imagine how much these vehicles on the streets are producing emissions, you will know what will be our environment for just next year. Emissions from such engines are huge and contribute really in global worming.

These engines, as it's known, have eight locations which produce air pollutants, such as: Crankcase, brake system, oil system and the main source is the exhaust system. Exhaust can produce many kinds of pollutants like: $\mathrm{CO}, \mathrm{CO}_{2}, \mathrm{NO}_{\mathrm{x}}, \mathrm{SO}_{\mathrm{x}}, \mathrm{HC}$ and Particulate Matters (PM). The relative amounts depend on engine design and operating conditions but they are of order: $\mathrm{NO}_{\mathrm{x}}$, 500-1000 ppm, CO: $200 \mathrm{~g} \mathrm{Kg}^{-1}$ of fuel, HC: $3000 \mathrm{ppm}$. Pollutant emissions can be substantially reduced by carefully controlling the characteristics of engine operation, particularly combustion. [1], [3]. A number of parameters affecting engine performance can influence the amount of emissions:

- The air-fuel ratio

- Rate of air-fuel mixing (oxygen content)

- Flame temperature
- Combustion lag

- Residence time

These, in turn, can be strongly influenced by the following:

- The fuel delivery system (including carbureted versus injected and sophistication of

- injection/carburetion technology)

- The size and shape of the cylinders and pistons

- The nature of the exhaust gas path (direct versus recirculated).[4],[6].

In addition, high compression ratios in the cylinders can increase fuel efficiency, decreasing directly the amount of $\mathrm{CO}_{2}$ emissions and, indirectly, $\mathrm{HC}$ and $\mathrm{CO}$ emissions.

There were very little study or last studies concerned with this subject. Many writers showed that the exhaust emissions will be reduced as the oxygen content is increased in the fuel-air mixture but no specific study studied this phenomenon, such studies are found in ANNEXES reports, 2000. [1]. Mueller and Martin $^{[5]}$, gave presented an experimental study to find 
a relation between the oxygenated fuel and the soot layer formation, their experiments were conducted at a $1200 \mathrm{rpm}$, moderate-load operating condition using a modern-technology, 4-stroke, heavy duty DI diesel engine with optical access. Images of broadband natural luminosity (i.e., light emission without spectral filtering) from the combustion chamber, coupled with heat-release and efficiency analyses, are presented for three kinds of test-fuels. One test-fuel (denoted GE80) was oxygenated with tri-propylene glycol methyl ether; the second (denoted BM88) was oxygenated with dibutyl maleate. The overall oxygen contents of these two fuels were matched at $26 \%$ by weight. The third testfuel (denoted $\mathrm{CN} 80$ ) was a non-oxygenated, 80-cetane blend of two $\mathrm{C} 16 \mathrm{H} 34$ primary reference fuels. The compositions of the three test-fuels were tailored such that each fuel had the same ignition delay at the given operating condition. Oxygen content, combustion phasing and adiabatic flame temperature also were carefully matched to isolate (as much as possible) the effects of oxygenate molecular structure on combustion and soot-formation processes.[5], [6].

The present study is an experimental one and it is applied on a Honda G 200 engine: Single cylinder with $197 \mathrm{cc}$ swept volume. The engine is run for a period of time until the cooling water and lubricating oil have been brought to define operating temperature. After a period of time the concentration of $\mathrm{CO}_{2}, \mathrm{CO}$ and $\mathrm{HC}$ are recorded, this represents the first part of the experimental work-running the engine without any oxygen feeding-. The second part of the experimental work is to inject pure oxygen before the throttle from a cylinder contains oxygen at 120 bar pressure, during full load engine operating.[9], [10].

The data are record in two cases: an engine with load and on the second part without load at different engine speeds (RPM). The final results are shown in Fig. 1-6.

\section{RESULTS}

Figure 1-6 shows the results of the present study and compare exhaust emission ratios of the studied engine in both cases with no excess oxygen feeding and with those in the present of oxygen feeding. In the present study $\mathrm{CO}_{2} \%, \mathrm{HC}(\mathrm{ppm})$ and $\mathrm{CO} \%$ are measured in two cases with load engine and without load engine and then with excess oxygen or without oxygen feeding. From Fig. 6 it can be noticed that the excess pure oxygen into the combustion systems improve their performance by changing the percentage or concentration of the combustion products.

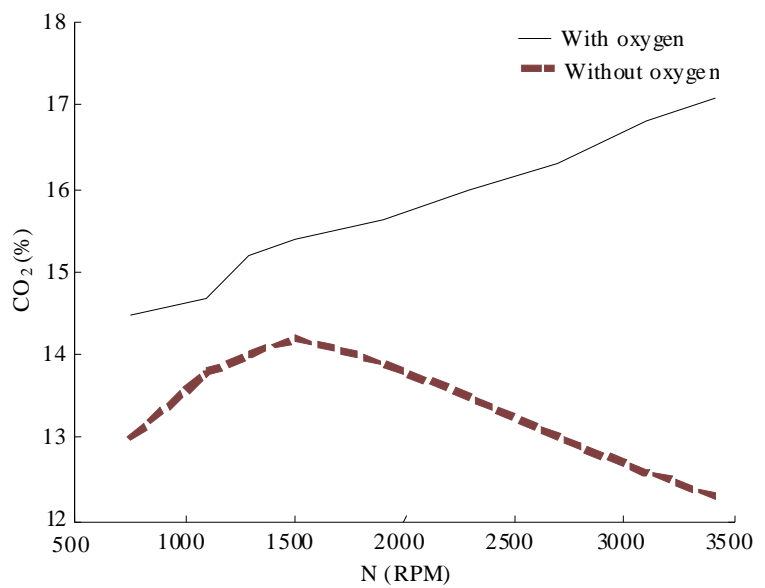

Fig. 1: $\mathrm{CO}_{2} \%$ Vs engine speed (RPM) with oxygen and without oxygen feeding with no load engine test

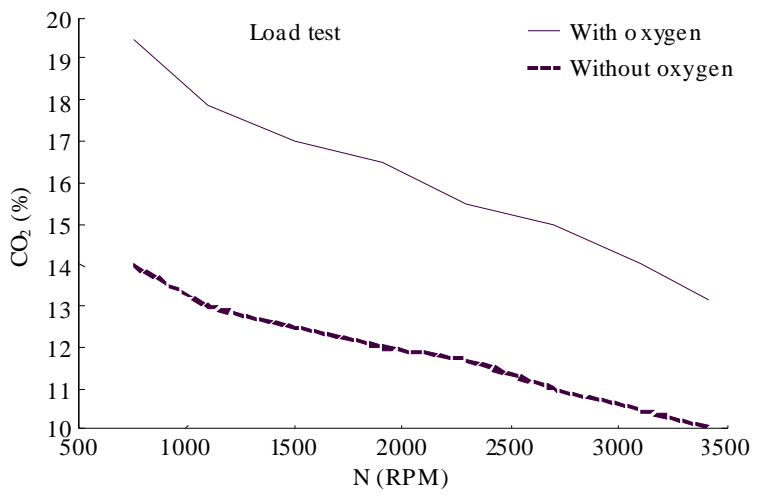

Fig. 2: $\mathrm{CO}_{2} \%$ Vs engine speed (RPM) with oxygen and without oxygen feeding

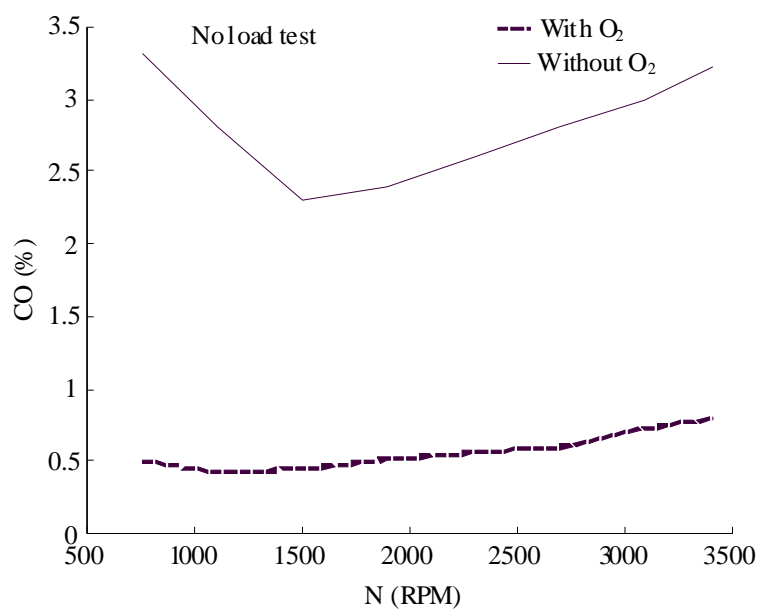

Fig. 3: CO\% Vs engine speed (RPM) with no load test 


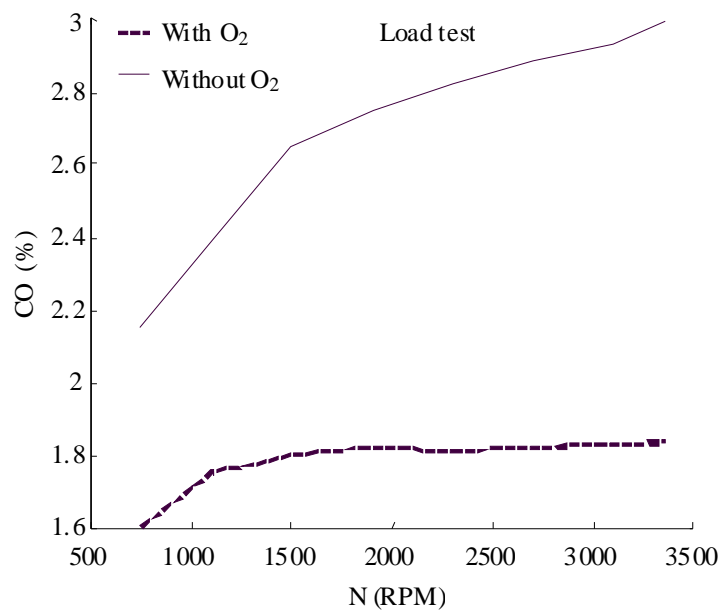

Fig. 4: CO\% Vs engine speed (RPM) with load test

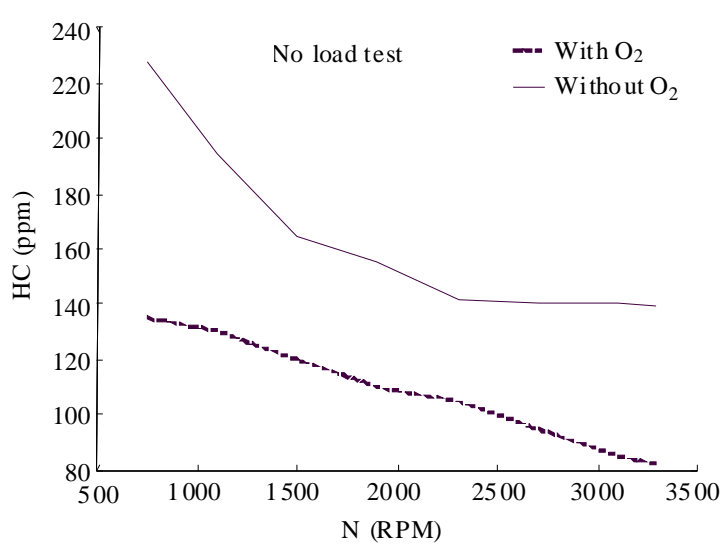

Fig. 5: HC (PPM) Vs engine speed (RPM)

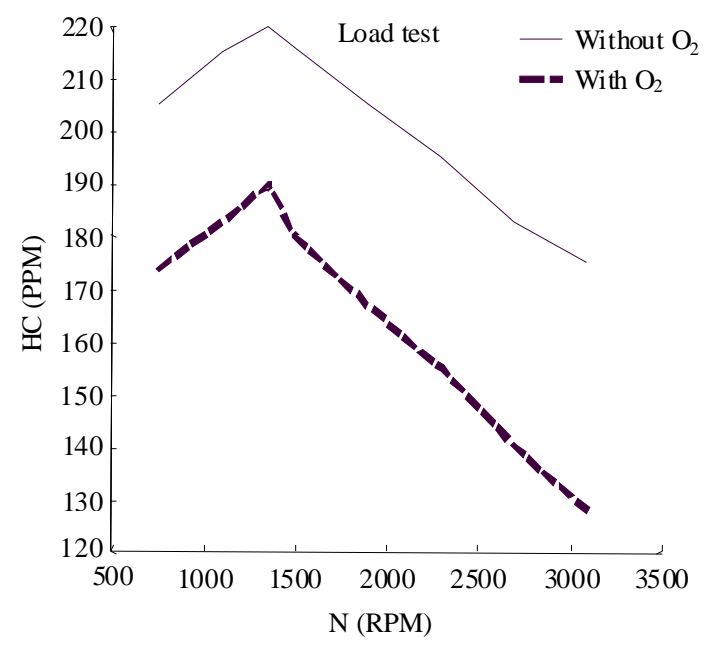

Fig. 6: HC (PPM) Vs engine speed (RPM)
Figure 1 shows that the $\mathrm{CO}_{2} \%$ is more in the case of more oxygen since more oxygen means that the chance of more complete combustion of fuel becomes possible, so more $\mathrm{CO}_{2}$ will produce. This can be noticed for the two cases: With load test Fig. 2 and without load testFig. 1. Another thing from Fig. 1-6 it can be noticed that $\mathrm{CO}_{2} \%$ increase as the engine speed increases at the case of no load test and without oxygen feeding, while for the same case and with the existence of oxygen feeding $\mathrm{CO}_{2} \%$ increases into some specific value $(\mathrm{RPM}=1500)$ then it decreases, the reason beyond that is as engine speed increases (with no load) it needs more oxygen and so $\mathrm{CO}_{2}$ formation will become less. In the contrary if there is a load in both cases with oxygen or with no oxygen the $\mathrm{CO}_{2} \%$ decreases as engine speed increase. Figure 3 and 4 show that the $\mathrm{CO} \%$ increases as the engine speed increases for the both cases with oxygen feeding or no oxygen feeding and for the two tests: with load and with no load, but the main thing is that $\mathrm{CO} \%$ in the case of oxygen feeding is much less than that of with no oxygen feeding. It can be noticed that $\mathrm{CO} \%$ in the case of oxygen feeding is less than that of with no oxygen feeding in order six times. Figure 5 and 6 show the HC in PPM Vs the engine speed, for the two loaded and no loaded cases. It can be notices that $\mathrm{HC}$ (PPM) decreases as the engine speed increase and the HC (PPM) with the existence of oxygen feeding is less than that of no oxygen feeding in order of about two times.

\section{DISCUSSION}

This study is considered as a base study in the field of research for saving fuel consumption. If such studies are continued the optimum ration between air (oxygen) and fuel will be reached. Results showed if more oxygen is feeding into the combustion chambers in any engine, then more combustion will be happened and bad emissions become less because they will be oxidized-as last figures showed. All exhaust emissions are decreased as more oxygen is fed into the combustion chambers. The exhaust analyzer results used in this study showed a good results compared with other engines tested without excess oxygen simultaneously. Also during the test the noise transmitted by the engine sound in the case with oxygen feeding is less than that without excess oxygen and the sound becomes softer.

\section{CONCLUSION}

From Fig. 6 and discussion demonstrated the following conclusions can be noticed: 
- $\mathrm{CO}_{2}$ concentration at oxygen injection test is greater than that at without oxygen injection at the two cases: With load and without load tests and at nearly all engine speeds.

- CO concentration at oxygen injection test is much less than that at without oxygen injection at the two cases: With load and without load tests and at nearly all engine speeds.

- HC concentration at oxygen injection test is less than that at without oxygen injection at the two cases: with load and without load tests and at nearly all engine speeds.

\section{REFERENCES}

1. API-agency, 2007. API-Reports USA. Direct web link: www.acde.ca.gov. pp:1-10.

2. Archie, W. and Culp J., 1991. Principles of Energy Conversion.., McGraw Hill, USA. ISBN: 10:007014902X, $2^{\text {nd }}$ Edition. pp: 576-580.

3. Beg, N., 1999. Scrappage programs. Annex to Thailand: Motorcycle Fleet Upgrade: Reducing Local and Global Emissions in Bangkok. Direct Web link: www.esmap.org/filez/pub/Thailand and reducing emissions Bangkok.pdf

4. Bose, R., 1998. Automotive energy use and emissions control: A simulation model to analyze transport strategies for Indian metropolises. Energy. Policy Journal, 26: 1001-1016:1-20. DOI: 10.1016/S0301-4215(98)00045-7
5. Charles, J., J. Mueller and Glen C., 2002. Effects of Oxygenated Compounds on Combustion and Soot Evolution in a DI Diesel Engine: Broadband Natural Luminosity Imaging. https://shop.sae.org/technical/papers/2002-01-1631

6. Eskeland, G. and Jimenez E., 1991. Choosing policy instruments for pollution control: A review. Direct web link:

http://econqa.worldbank.org/external/default/main? pagePK=64165259\&theSitePK=469372\&piPK=64 $165421 \&$ menuPK $=64166093 \&$ entityID $=00000926$ 5_3961001045114

7. John, B., 1988. Internal Combustion Engine Fundamentals. McGgraw Hill, USA., ISBN: 10:007028637X, $2^{\text {nd }}$ Edn., pp:850- 930.

8. Minato, K., 2000. Automotive technology and regulations on fuel economy and exhaust emissions. JSAE J., 54: pp:11-17.

9. Richard, S., 1992. Introduction to Internal Combustion Engines. The Macmillan Press Ltd., pp: 400-574.

10. Wall Street Journal, 2006 .Ford, GM Push to Promote 'Flex Fuel' Vehicles, January 10, 2006. Direct web link: www.enviromena,com, or www.evworld.com 